\title{
Gender Flexibility, but not Equality: Young Adults' Division of Labor Preferences
}

\author{
Brittany N. Dernberger, ${ }^{a}$ Joanna R. Pepin ${ }^{b}$
}

a) University of Maryland; b) University of Texas at Austin

Abstract: Rising acceptance of mothers' labor force participation is often considered evidence of increased support for gender equality. This approach overlooks perceptions of appropriate behavior for men and gender dynamics within families. We use nationally representative data of 12 th-grade students from Monitoring the Future surveys (1976 to 2014) to evaluate changes in youths' preferred division of labor arrangements. Over this period, contemporary young people exhibited greater openness to a variety of division of labor scenarios for their future selves as parents, although the husband-as-earner/wife-as-homemaker arrangement remained most desired. Using latent class analysis, we identify six configurations of gender attitudes: conventionalists, neotraditionalists, conventional realists, dual earners, intensive parents, and strong intensive parents. There are no gender egalitarian configurations-exhibiting equal support for both parents' time at work and time at home. Our findings indicate researchers must distinguish between adoption of gender egalitarian principles and gender flexibility in dividing time at work and at home.

Keywords: gender; family; working parents; inequalities; attitudes; division of labor

Citation: Dernberger, Brittany N., and Joanna R. Pepin. 2020. "Gender Flexibility, but not Equality: Young Adults' Division of Labor Preferences." Sociological Science 7: 36-56.

Received: November 20, 2019

Accepted: December 14, 2019

Published: January 21, 2020

Editor(s): Jesper Sørensen, Sarah Soule

DOI: $10.15195 /$ v7.a2

Copyright: (C) 2020 The Author(s). This open-access article has been published under a Creative Commons Attribution License, which allows unrestricted use, distribution and reproduction, in any form, as long as the original author and source have been credited. (1) (1)
ESPITE convergence in men's and women's time spent in paid and unpaid labor, contemporary family life continues to be unequal and highly gendered (Damaske 2011; Doan and Quadlin 2019; England 2010; Jacobs and Gerson 2005; Sayer 2005). One dominant explanation for continued inequality in the private sphere is that institutional constraints, such as stagnant workplace policies, have not kept pace with changing preferences for gender equality at home and at work (Cotter, Hermsen, and Vanneman 2011; Jacobs and Gerson 2016; Pedulla and Thébaud 2015; Scarborough, Sin, and Risman 2018; Thébaud and Halcomb 2019). Undeniably, support for mothers' labor force participation has increased over time, and contemporary young couples report they hope to "have it all," fairly sharing employment and family responsibilities (Bolzendahl and Myers 2004; Brewster and Padavic 2000; Cotter et al. 2011; Gerson 2009, 2011; Scarborough et al. 2018; Thornton and YoungDeMarco 2001). Bolstering this perspective, experimental evidence demonstrates men and women prefer an egalitarian relationship when institutional constraints are removed (Pedulla and Thébaud 2015). Consequently, many scholars conclude that the main deterrents to further gender equality require changing the structural barriers embedded in workplace polices and practice (Gerson 2009, 2011; Hoffnung 2004; Raley, Crissey, and Muller 2007; Thornton and Young-DeMarco 2001).

This account assumes that the growing acceptance of mothers' employment reflects a broad trend favoring gender equality more generally. We contend that prior studies have been unable to adequately evaluate this assumption for two reasons. First, many studies do not comprehensively consider public and private realms simultaneously. Ample evidence shows greater support for gender equality 
in the public sphere of employment than in the private sphere of the family, and gender attitudes have shifted at different paces between these spheres (England 2010; Knight and Brinton 2017; Pepin and Cotter 2018; Scarborough et al. 2018). Mothers' employment is likely the most socially acceptable element of gender egalitarianism. Thus, indicators that narrowly measure support for mothers' labor force participation may overstate support for gender equality, overlooking less egalitarian attitudes about gender in the private sphere. Second, studies predominately focus on women's place in society, at the exclusion of measuring attitudes about men's behavior (England 2010; Friedman 2015). Alongside declining conventional gender attitudes, increased commitment to gender egalitarianism should also result in growing support for gender atypical arrangements, such as mothers working full time and fathers working part time or staying at home. To adequately capture gender egalitarian beliefs, measures of gender attitudes would ideally include a two-by-two design that encompasses appropriate behavior for men and women in both public (employment) and private (marriage and children) spheres.

This study contributes new insights into established assumptions about the prevalence of support for gender egalitarian principles- the belief that fathers and mothers should equally share time at work and time at home-by evaluating perceptions of fathers' and mothers' behavior in both public and private spheres. We use data from Monitoring the Future surveys (1976 to 2014), a nationally representative probability sample of 12th-grade students, to examine whether increasing proportions of young people prefer parents equally sharing time at work and time at home. We focus on adolescents' preferences for their future family life because of their potential to reveal shifts in social norms, which is increasingly important as greater diversity in family types has resulted in weakened institutional mechanisms dictating family life (Giddens 1992; Yodanis and Lauer 2014). Adults' gender attitudes are already aligned with the realities of adulthood, so our findings from youth respondents are not measures of post hoc explanations for adult behavior. Focusing on changes in youth attitudes eliminates age effects and allows us to evaluate cohort changes.

We find that even among high school students, a conventional arrangementconsisting of a husband working full time and the wife staying at home-remains the most desired. We further evaluate the latent belief structures that adolescents hold by conducting a latent class analysis (LCA) to analyze the underlying response patterns. Consistent with prior research, we find decreasing numbers of traditionalists, those who oppose mothers' employment entirely (Cotter et al. 2011; Scarborough et al. 2018), but these traditionalist beliefs were not replaced by desires for fathers and mothers to be equal in their earning and caring responsibilities. Our analyses revealed that youth continued to prefer conventional arrangements, but they were now more open to other possibilities than prior generations. These findings challenge previous research suggesting persistent, albeit slow, trends toward increasing values of gender equality. Our findings suggest that researchers must distinguish gender egalitarian principles from flexibility in dividing paid and unpaid labor to understand the future of the gender revolution. 


\section{Place: Public and Private Spheres}

Attitudes about gender are not monolithic; people exhibit more support for gender equality in the public realm than in the private sphere of the family (England 2010; Jacobs and Gerson 2016; Kane and Sanchez 1994; Knight and Brinton 2017; Mason and Lu 1988; Pepin and Cotter 2018; Scarborough et al. 2018). There is almost universal support for egalitarianism in the public sphere, such as women having the same job opportunities as men (Cotter et al. 2011; Pepin and Cotter 2018; Scarborough et al. 2018). Still, most people continue to rely on gender as a dominant framework for assigning household chores and child care (Doan and Quadlin 2019). The mid-1990s emergence of egalitarian essentialism-attitudes about gender that blend principles of equality with beliefs in innate gender dissimilarities-underscores the need to look at attitudes about public and private spheres concurrently (Charles and Grusky 2004; Cotter et al. 2011; Pepin and Cotter 2018).

This divergence in gender attitudes between spheres is widespread, even among young people who are the most supportive of gender equality (Cotter et al. 2011). Although adolescents increasingly support mothers' labor force participation, their support for gender equality in families plateaued in the mid-1990s and in some instances regressed (Pepin and Cotter 2018; Thornton and Young-DeMarco 2001). One explanation for the uneven changes in gender attitudes is that attitudes about gender in the public sphere are tied to general beliefs about broader social constructs, such as support of individualism (Brooks and Bolzendahl 2004). Acceptance of mothers' labor force participation may be an exemplar of belief in individualism, whereas beliefs about household labor may not be strongly associated with rightsbased values.

Although it is possible that greater acceptance of mothers' employment represents increased support for gender equality, ${ }^{1}$ another interpretation is that these gender attitudes shifted as people recognized families need two incomes. Families can better absorb the shock of adverse events, such as job loss, by having both parents in the labor market; this "risk pooling" both maximizes household earnings and reduces economic uncertainty (Cherlin 2014; Western et al. 2012). In this context, support for mothers' labor force participation may reflect a reaction to economic changes rather than diminishing conventional attitudes that prioritize mothers' time with children over fathers' time caregiving. Analyses that fail to measure support for gender atypical arrangements-scenarios in which the husband's time at home is prioritized-risk positively biasing the estimated support for gender equality, measuring only the most socially acceptable facet of gender egalitarianism, namely mothers' employment.

\section{Gender: The Role of Men}

One explanation for the stalled gender revolution is that most of the changes thus far have been brought about by changes in women's behavior (England 2006, 2010). But continued progress may depend on increasing acceptability, even desirability, of men taking on behaviors historically seen as feminine (Friedman 2015). Some gender scholars have posited that the adoption of intensive parenting norms-child- 
centered, time-consuming, and expensive parenting styles-may promote greater commitment to egalitarian practices, such as involved fatherhood (Edin and Nelson 2013; Gerson 2011; Hays 1996; Pedulla and Thébaud 2015; Williams, Blair-Loy, and Berdahl 2013). Contemporary fathers spend about triple the time caring for children compared with their 1965 counterparts (Livingston and Parker 2019).

We posit, however, that changes in the meaning of fatherhood may not be a good indicator of gender egalitarian principles. Just as economic events may bring about changes in mothers' employment without undermining conventional gender attitudes, support for involved fathering may be a reaction to an economic need to bolster children's chances in a time of greater economic precarity, rather than men's desire to take on an equal share of parenting. A turn toward intensive fathering may be motivated by parents' vigilance in leveraging all available resources to ensure social and economic advantage can be passed on to their children (Cooper 2014; Sherman 2017). We suggest that evaluations of division of labor configurations should vary both men's and women's time in employment and at home to analytically separate gender from the division of labor arrangement (e.g., the wife should be a homemaker versus the importance of one parent, regardless of gender, staying home).

\section{Data and Methods}

We use Monitoring the Future data, an annual survey given to a nationally representative group of American 12th-grade students since 1976 (Johnston et al. 2017). Approximately 16,000 students are administered questionnaires in their classrooms, distributed across 133 public and private high schools around the country. The respondents are primarily 17 or 18 years old at the time of the survey. Five versions of the questionnaire are distributed, with core questions asked of all respondents and then specific questions appearing on each of the five forms. ${ }^{2}$ The variables pertinent to this research appeared on form 2 of the surveys from 1976 until $2014 .^{3}$ The number of respondents completing form 2 varied from 2,170 to 3,775 per year.

\section{Dependent Variables}

Our dependent variables stem from a consistently asked vignette regarding attitudes toward imagined work and family arrangements. Respondents were instructed: "Imagine you are married and have one or more preschool children. How would you feel about each of the following working arrangements: (1) husband works full time, wife doesn't work; (2) husband works full time, wife works about half time; (3) husband doesn't work, wife works full time; (4) husband works about half time, wife works full time; (5) both work about half time; and (6) both work full time." Imagining a household scenario with preschool-aged children is a common measure used to capture attitudes about working women and relationship quality, with variations included in the General Social Survey, International Social Survey Program, and the National Study of Families and Households (Davis and Greenstein 2009). This scenario also reflects living arrangements for many American households. Although the number of single parents has increased, 66 percent of 
all children younger than age six lived with two married parents in 2014, the last year of our data (authors' calculation from Flood et al. 2018). Because of the time intensity of these parenting years, focusing on attitudes about married families with preschoolers is an important scenario.

For each possible arrangement, survey respondents indicated if they thought the division of labor scenario was not at all acceptable, somewhat acceptable, acceptable, or desirable. We group the arrangements into three types: (1) traditional arrangements in which the husband works full time and the wife doesn't work or works part time; (2) matched arrangements in which both parents work full time or part time; (3) and gender atypical arrangements in which the husband does not work or works part time and the wife works full time. Descriptive statistics for the dependent variables are provided in Table A of the online supplement.

\section{Independent Variables}

Our primary independent variable is an ordinal measure of the survey year, ranging from 1976 to 2014. To account for contextual changes that potentially confound the identified trends in attitudes, multivariate analyses include respondents' demographic characteristics associated with attitudes about gender. The descriptive statistics for these control variables are presented in Table 1 . We construct a combined nominal variable of gender and race for this analysis: white men (42 percent), white women (43 percent), black men (6 percent), and black women (8 percent). We restrict the analytic sample to white and black youth because data on other races and ethnicities were not consistently available across the survey years.

Previous scholarship showed attitudes about gender were associated with mother's labor force participation and education (Bolzendahl and Myers 2004; Meagher and Shu 2019; Tallichet and Willits 1986). Thus, we use a categorical variable indicating respondents' mother's highest level of education (grade school or less, some high school, high school, some college, bachelor's degree, or more than a bachelor's degree). To determine respondents' mother's employment status, youth chose from a four-item frequency scale indicating how consistently their mother had a paid job with at least part-time hours while they were growing up: not employed, employed sometimes, employed most of the time, and employed consistently.

Exposure to one's own mother's employment is more likely in single-mother households or in families that experience instability in household composition. Theoretically, in two-parent households, how one's parents divided labor while growing up is expected to be associated with perceptions of the division of labor as an adult. Thus, we combine two questions asking respondents if their mother (or female guardian) or father (or male guardian) live in the same household with them to create a four-category family structure variable: live with both parents, live with their mother only, live with their father only, and live with neither their mother nor father. We also control for religiosity because some forms of religiousness are associated with holding conservative views, but there are important gender differences in this link (Schnabel 2018). Religiosity was measured by respondents' frequency of attendance at religious services: never, rarely, once or twice a month, 
Table 1: Percentage distribution of independent variables, 1976 to 2014

\begin{tabular}{|c|c|c|c|c|c|}
\hline & All & $\begin{array}{l}\text { White } \\
\text { Men }\end{array}$ & $\begin{array}{c}\text { White } \\
\text { Women }\end{array}$ & $\begin{array}{l}\text { Black } \\
\text { Men }\end{array}$ & $\begin{array}{c}\text { Black } \\
\text { Women }\end{array}$ \\
\hline & & $42 \%$ & $43 \%$ & $6 \%$ & $8 \%$ \\
\hline \multicolumn{6}{|l|}{ Mother's Education } \\
\hline Less than high school & 0.13 & 0.10 & 0.13 & 0.19 & 0.24 \\
\hline High school & 0.38 & 0.39 & 0.38 & 0.34 & 0.33 \\
\hline Some college & 0.19 & 0.18 & 0.19 & 0.19 & 0.20 \\
\hline College & 0.21 & 0.23 & 0.21 & 0.21 & 0.15 \\
\hline College + & 0.09 & 0.10 & 0.10 & 0.08 & 0.08 \\
\hline \multicolumn{6}{|l|}{ Mother's Employment } \\
\hline Not employed & 0.22 & 0.24 & 0.23 & 0.10 & 0.10 \\
\hline Employed sometimes & 0.27 & 0.29 & 0.28 & 0.18 & 0.17 \\
\hline Employed most of the time & 0.18 & 0.19 & 0.17 & 0.20 & 0.18 \\
\hline Consistently employed & 0.34 & 0.29 & 0.33 & 0.52 & 0.55 \\
\hline \multicolumn{6}{|l|}{ Family Structure } \\
\hline Both parents & 0.74 & 0.79 & 0.78 & 0.46 & 0.46 \\
\hline Mom only & 0.17 & 0.13 & 0.14 & 0.38 & 0.42 \\
\hline Dad only & 0.03 & 0.04 & 0.03 & 0.04 & 0.03 \\
\hline Neither parents & 0.05 & 0.04 & 0.05 & 0.12 & 0.10 \\
\hline \multicolumn{6}{|l|}{ Religiosity } \\
\hline Never attend services & 0.13 & 0.15 & 0.12 & 0.09 & 0.06 \\
\hline Rare attendance & 0.35 & 0.36 & 0.35 & 0.35 & 0.28 \\
\hline Monthly attendance & 0.17 & 0.16 & 0.17 & 0.22 & 0.23 \\
\hline Weekly attendance & 0.35 & 0.32 & 0.37 & 0.34 & 0.44 \\
\hline \multicolumn{6}{|l|}{ Region } \\
\hline Northeast & 0.22 & 0.23 & 0.24 & 0.15 & 0.15 \\
\hline North Central & 0.32 & 0.34 & 0.34 & 0.18 & 0.18 \\
\hline South & 0.36 & 0.33 & 0.32 & 0.63 & 0.63 \\
\hline West & 0.10 & 0.11 & 0.10 & 0.04 & 0.04 \\
\hline $\mathrm{N}$ & 75,573 & 32,042 & 32,574 & 4,852 & 6,105 \\
\hline
\end{tabular}

Notes: Monitoring the Future Surveys (1976 to 2014). Descriptive statistics are weighted; list-wise deletion was used to address missing data.

or about once a week or more. People in different regions of the country vary in their endorsement of egalitarian ideology (Bolzendahl and Myers 2004), and we include a region variable constructed from the four United States Census Bureau regions of the country: Northeast, North Central, South, and West. After restricting the sample to white and black youth and using list-wise deletion to address missing cases given the large sample size, our total analytic sample consisted of 75,573 respondents. The detailed construction of the sample is shown in Table B of the online supplement.

\section{Analytic Strategy}

We begin by using descriptive statistics to examine trends in youths' evaluation of each of the six division of labor arrangements. We then use two approaches 
to better understand how youths' attitudes about the division of labor changed over time. First, we examine the trends in young adults' evaluations of their future families by conducting a series of multinomial logistic regressions for each of the division of labor arrangements, accounting for the other independent covariates. Although we considered an ordinal logistic regression, results from a Brant test (Brant 1990) indicated the parallel regression assumption—an assumption that the coefficient for each variable in the separate cumulative logit models was identicalwas violated for several variables. All analyses use the sample weights, and for ease of interpretation of the model, we plot the predicted averages of each agreement category by the division of labor arrangement, holding all other model variables at their means. Replication code for data access and all paper analyses are available at https://osf.io/m3xwy/.

Second, we conduct LCAs of the six division of labor arrangements to assess the underlying response patterns that are unobservable in the multinomial regression models. Employing a LCA allows us to model youths' gender ideology across sphere and gender that cannot be directly observed in the individual trends. The multinomial models identify patterns for each arrangement separately, but LCA acknowledges that the assessments of each arrangement are not independent. Gender egalitarianism is multidimensional, and LCA allows us to leverage each of those dimensions simultaneously to see the underlying patterns. To analyze the multivariate categorical data, we used the $\mathrm{R}$ statistical software package poLCA (Linzer and Lewis 2013).

We then plot the historical trajectory of these classes by race-gender groups. If the attitudes reflect widespread norms, there should be minimal demographic differences in the trajectories. Prior research suggests there may be distinctions in attitudes by gender and race. Thus, we disaggregate attitudes by race-gender groups to investigate whether trends are being driven by a particular subpopulation. Even though men and women may both report desires for egalitarian relationships, they have opposing approaches to fall back on if their egalitarian desires are unattainable: most women identify financial self-reliance, whereas most men emphasize a neotraditional arrangement in which the husband works full time and the wife works part time (Gerson 2009). Although prior research is inconclusive about racial differences in egalitarian beliefs, black mother's historical participation in paid employment at a higher rate than white mothers may influence perceptions of ideal work and family arrangements (Carter, Corra, and Carter 2009; Harris and Firestone 1998; Hershey 1978; Kane 2000; Mason and Lu 1988).

\section{Results}

We estimated multinomial models to evaluate trends in youths' assessments of six division of labor arrangements, adjusted for changes in demographic characteristics of the population. The coefficients of the multinomial analyses can be found in Tables $\mathrm{C} 1$ to $\mathrm{C} 3$ of the online supplement. For ease of model interpretation, we present Figure 1, the predicted proportion of youth in each survey year who evaluated each of the six division of labor arrangements as desirable, acceptable, or not at all acceptable, holding the other model variables constant at their mean. We 

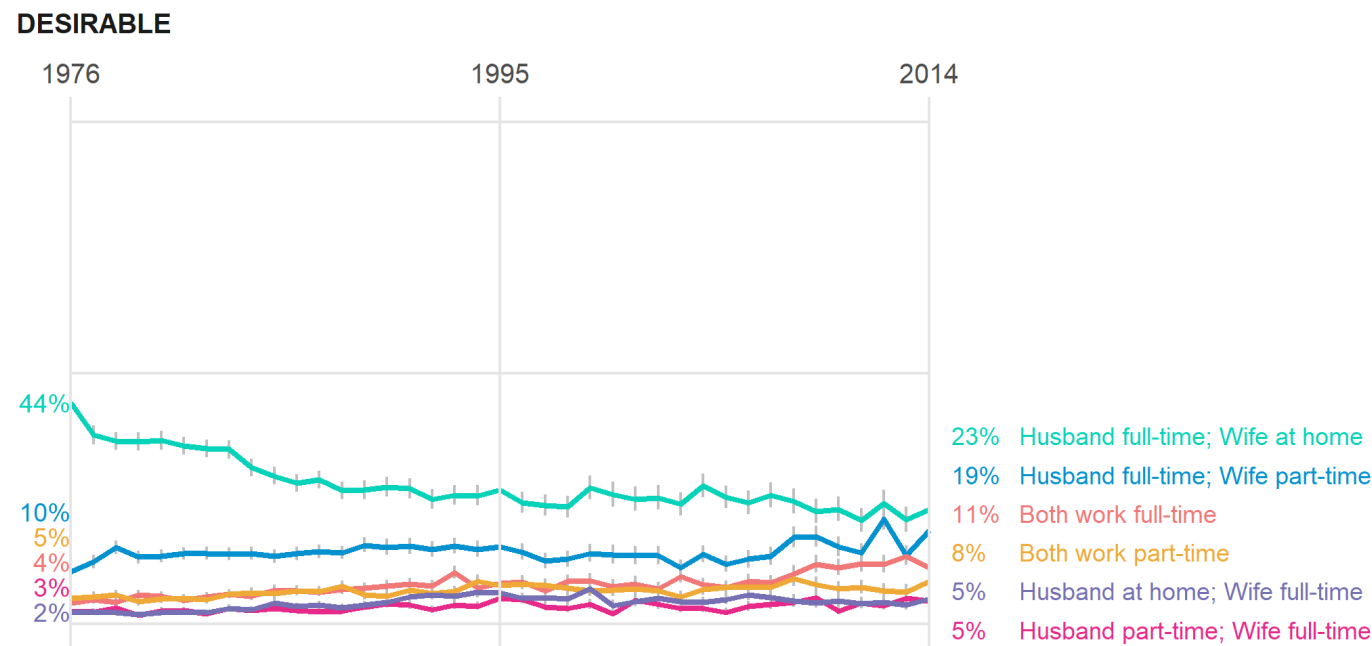

ACCEPTABLE



$56 \%$ Husband full-time; Wife part-time $41 \%$ Husband full-time; Wife at home $31 \%$ Both work part-time

$25 \%$ Husband part-time; Wife full-time $24 \%$ Both work full-time

$20 \%$ Husband at home; Wife full-time

NOT AT ALL ACCEPTABLE

Figure 1: Young adults' expectations of the division of work and family labor. Note that the "Somewhat Acceptable" response is not shown. 
discuss three important patterns illustrating youths' division of labor preferences over time. First, the arrangements with the greatest desirable or acceptable rankings in 2014 continued to be traditional arrangements in which men are employed full time. The conventional arrangement-consisting of a husband working full time and the wife staying at home-remained the most desired arrangement, even as the desirability for this arrangement decreased from 44 percent in 1976 to 23 percent in 2014. A neotraditional arrangement, with a husband working full time while the wife works part time, was the most acceptable arrangement across all survey years. These trends show little evidence that youth have embraced gender egalitarian ideals, as they continue to desire arrangements in which the husband works full time and the wife prioritizes family responsibilities.

The second development was the striking increase in acceptability of mothers' employment, which was consistent with prior literature on changes in gender attitudes. The matched arrangements (both spouses work part time or both work full time) and gender atypical arrangements (wife is employed full time and husband is a homemaker or employed part time) were increasingly viewed as acceptable. Most dramatic, the unacceptability of both parents working full time decreased from 72 percent in 1976 to 35 percent in 2014. Desirability for this full-time, dual-earner arrangement was less pronounced, rising from 4 percent in 1976 to 11 percent in 2014. Rising acceptance of mothers' employment was also evident by the growing unacceptability of a conventional husband-earner/wife-homemaker arrangement.

The third key trend was the minimal increase in desirability for the gender atypical arrangements. Over time, fewer youth evaluated these gender atypical situations as unacceptable; however, gender atypical arrangements were desired by 5 percent or fewer youth across all survey years. These findings are consistent with the expectations that comprehensive survey measures that incorporate attitudes about men's behavior reveal less support for equal role distribution between men and women (Braun 2008; Walter 2018). Notably, changes in the unacceptability of the gender atypical arrangements largely occurred before the mid-1990s, as apparent by the gentler slope of change beginning in about 1995 .

To summarize, youth were more open to a variety of division of labor scenarios over time. This finding is consistent with prior literature documenting an increasing acceptance of mothers' labor force participation. Still, the conventional arrangements in which husbands were employed full time and mothers stayed at home or worked part time continued to be the most desired and accepted arrangements in 2014. We suggest that gender flexibility, that is, the greater openness to multiple arrangements, is not the same as the desire for men and women's equal time at work and at home, which is often inferred by measures of accepting mothers' employment.

It is difficult to discern by analyzing these arrangements separately whether there have been changes in the evaluations of the possibilities as a collective. We could be overstating the persistence of conventionalism if some of the respondents who reported they desired the conventional arrangements are the same youth who are also open to the other arrangements. For example, of the 23 percent of youth who desire a conventional husband full time/wife at home arrangement in 2014, 5 percent of them could also have reported they desired a wife working full 
time while the husband stays at home, if gender were irrelevant and they were prioritizing a parent at home with the preschool child. To address this possibility, we employed an LCA to analyze the underlying response patterns, allowing us to assess the latent belief structures that adolescents hold. This serves as sort of a robustness test of our conclusions.

\section{Latent Class Analysis}

An LCA facilitates our ability to comprehensively evaluate the underlying patterns of youths' assessments of the division of labor for their future selves. An LCA approach enables us to consider the attitude preferences simultaneously rather than treating each arrangement as independent. The LCA shows whether any clusters are gender egalitarian, reflecting equal preferences for both parents' time at work and time at home. We used a three-step approach to identify configurations of attitudes about the division of labor. The first goal of LCA is to identify groups that share similar patterns among respondents' assessment of the six division of labor arrangements (i.e., latent classes) (Bonikowski and DiMaggio 2016). Determining the appropriate number of typologies is often not straightforward and requires assessments of both fit indices and theoretical framing (Collins and Lanza 2010; Nylund, Asparouhov, and Muthén 2007). We calculated several fit metrics, shown in Table 2, and chose the most conceptually meaningful model when the metrics were in conflict. Following prior literature, we relied primarily on identifying the model with the lowest adjusted Bayesian information criterion (BIC) value, in which lower scores indicate better fit, and the highest entropy value, in which higher values indicate more distinct classes (Raftery 1995; Schwarz 1978).

We examined models with one to eight latent classes, using the pooled data set containing 38 survey years from 1976 to 2014. The adjusted BIC value declined with each additional class. We generated an elbow plot (see Figure A in the online supplement) and identified six or seven classes as the turning point where additional classes no longer significantly decreased the BIC. The entropy value had a higher value with 6 classes than with 7 classes, meaning the distinction between classes declined with seven latent classes compared with six latent classes. The model with six-classes had a low BIC score while maintaining a relatively high entropy value, indicating it was potentially a better fit than the model with sevenclasses. We further assessed the robustness of the six-class model compared with the seven-class model by examining the proportion of respondents in each class. The six-class model contained one group with 3 percent of respondents and the remaining groups consisted of at least 12 percent of respondents. The seven-class model resulted in one class containing fewer than 3 percent of respondents and another with fewer than 10 percent of respondents. Interpretation of seven classes did not meaningfully change our findings. ${ }^{4}$ We selected the model containing six empirically based classifications, with adequate distribution of respondents among the classes, a low BIC score, and a relatively high entropy score.

In the second step of the three-step LCA approach, respondents are assigned a latent class. Posterior probabilities-the probability of membership of each classwere estimated for each respondent. Respondents were assigned to the class with 
Table 2: Latent class model fit statistics $(n=75,573)$

\begin{tabular}{|c|c|c|c|c|c|c|c|}
\hline $\begin{array}{l}\text { k } \\
\text { Classes }\end{array}$ & $\begin{array}{c}\text { Log- } \\
\text { Likelihood }\end{array}$ & $\begin{array}{l}\text { Residual } \\
\text { Degrees } \\
\text { of } \\
\text { Freedom }\end{array}$ & $\begin{array}{l}\text { Bayesian } \\
\text { Information } \\
\text { Criterion }\end{array}$ & $\begin{array}{c}\text { Consistent } \\
\text { Akaike } \\
\text { Information } \\
\text { Criterion }\end{array}$ & $\begin{array}{l}\text { Likelihood } \\
\text { Ratio }\end{array}$ & Entropy & $\begin{array}{c}\text { Bayesian } \\
\text { Information } \\
\text { Criterion } \\
\% \text { Change }\end{array}$ \\
\hline 1 & $-528,193$ & 4,077 & $1,056,587$ & $1,056,605$ & $123,606.8$ & - & - \\
\hline 2 & $-500,831$ & 4,058 & $1,002,077$ & $1,002,114$ & $68,882.9$ & 0.83 & -5.16 \\
\hline 3 & $-493,625$ & 4,039 & 987,878 & 987,934 & $54,470.7$ & 0.73 & -1.42 \\
\hline 4 & $-487,835$ & 4,020 & 976,512 & 976,587 & $42,891.3$ & 0.77 & -1.15 \\
\hline 5 & $-483,663$ & 4,001 & 968,382 & 968,476 & $34,547.9$ & 0.76 & -0.83 \\
\hline 6 & $-481,026$ & 3,982 & 963,321 & 963,434 & $29,273.2$ & 0.75 & -0.52 \\
\hline 7 & $-478,452$ & 3,963 & 958,387 & 958,519 & $24,126.0$ & 0.73 & -0.51 \\
\hline 8 & $-477,275$ & 3,944 & 956,247 & 956,398 & $21,772.4$ & 0.74 & -0.22 \\
\hline
\end{tabular}

Note: The selected model consisted of 6 classes.

the highest membership probability. The response patterns for each of the division of labor arrangements within the six classes are presented in Figure 2. The figure shows the predicted responses for each of the division of labor scenarios from a model with the control variables, conditional on class membership. The details of the conditional probabilities for the responses for each of the division of labor arrangements by class are available in Table D of the online supplement.

We labeled the six latent classes for ease of interpretation and discuss them next. The conventional class, 26 percent of the sample, is the group most likely to evaluate a conventional work-family arrangement as desirable. These respondents also evaluated a neotraditional arrangement as somewhat acceptable or acceptable, whereas viewing the remaining work-family arrangements almost exclusively as unacceptable. Neotraditionalists (21 percent of respondents) and conventional realists (23 percent) evaluated a conventional arrangement as desirable, but they were more likely than conventional respondents to report a neotraditional arrangement as acceptable or somewhat acceptable. They were also more likely than conventional respondents to report a dual-earning arrangement as somewhat acceptable. Compared with the neotraditionalists, conventional realists were more likely to indicate that the gender atypical arrangements were somewhat acceptable rather than unacceptable.

The dual-earner class of respondents, consisting of 12 percent of the sample, were more likely than other groups to rate the full-time, dual-earning arrangement as desirable or acceptable. On the surface, this group may appear to embrace an egalitarian arrangement, but we argue that that interpretation is misleading for two reasons. First, this group was strongly against men not being in the labor force, almost universally rating the husband as homemaker/wife employed full time arrangement as unacceptable. Second, this group was least likely to rate the neotraditional arrangement as unacceptable out of all six arrangements. Hence, the response patterns of the dual-earner group are consistent with research suggesting that when desires for an egalitarian partnerships-in this case, dual-earning 


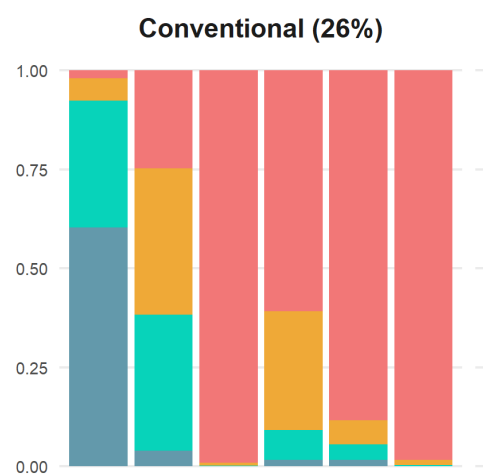

Dual-earners (12\%)

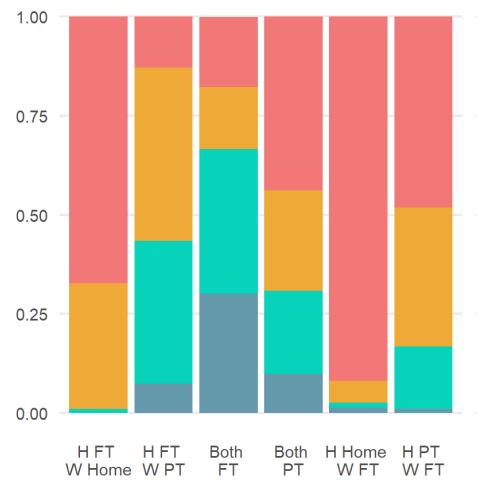

Neotraditional (21\%)

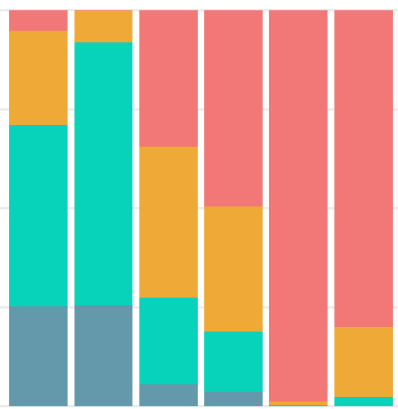

Intensive Parents (15\%)

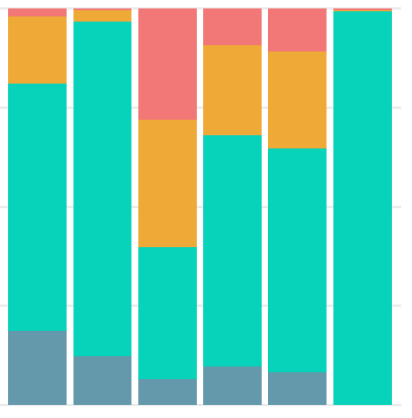

$\begin{array}{lcccc}\text { HFT } & \text { HFT } & \text { Both } & \text { Both } & \text { HHome } \\ \text { W Home } & \text { WPT } & \text { FT } & \text { PT } & \text { WFT } \\ \text { WFT }\end{array}$
Conventional Realists (23\%)

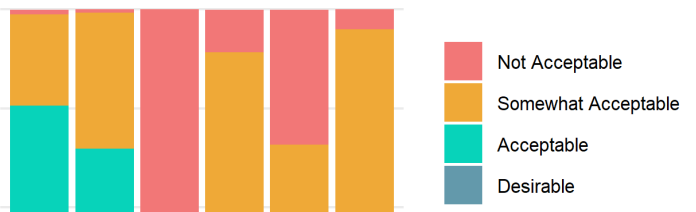

Figure 2: Predicted proportion of evaluations for each arrangement by class. Detailed conditional probabilities for responses to each division of labor arrangement by class are available in Table $\mathrm{D}$ of the online supplement. FT, full time; $\mathrm{H}$, husband; PT, part time, W, wife.

arrangements-are not possible, the fallback plan continues to be a neotraditional arrangement (Gerson 2009).

The intensive parents ( 15 percent of the sample) and strong intensive parents ( 3 percent of the sample) appeared much more open than other respondents to a range of work-family arrangements. This pattern of responses points to a concern about time available for the preschool child mentioned in the vignette. These respondents disliked the full-time, dual-earning arrangement, instead preferring someone, of either gender, to be at home with the preschool child. In reality, that someone would almost always be the mother (Gerson 2011; Sherman 2017). The strong intensive parents group showed a similar pattern as the intensive parents, but they were more likely than intensive parents to evaluate most work-family arrangements as desirable rather than acceptable. One interpretation of these two groups is that they are simply open to a range of possibilities, including gender atypical arrangements. We refrained from labeling either of these groups as gender egalitarian because they were more likely to consider the most equal arrangement, in which both parents work full-time, as unacceptable or only somewhat acceptable compared with the other work-family arrangements. These clusters are consistent with explanations 
that cultural norms of intensive parenting may facilitate greater acceptance of one parent-regardless of gender-being at home.

In the third and final step, we conducted a multinomial logistic regression model to evaluate changes over time in class membership. Figure 3 presents the changes in the predicted proportion of class membership disaggregated by race-gender groups, adjusting for respondents' demographic characteristics by holding these variables at their means. Because of the small number of respondents assigned to the strong intensive parenting group, especially once broken down by survey year and race-gender groups, we combined the two intensive parenting groups in this final analysis. The trends without the disaggregation are available in Figure $C$ of the online supplement.

The first trend to note is the dramatic decrease over time in the proportion of youth who were classified in the conventionalist group. In 1976, nearly 60 percent of young white men were conventionalists; by 2014, only sixteen percent of young white men were in this group. A similar, if less steep, decline in conventionalists is apparent for the remaining race-gender groups. With the exception of white women, the likelihood of belonging to the neotraditional class remained relatively persistent across the survey years. For young white women, about 28 percent belonged to the neotraditional group in 1976, declining to about 12 percent of young white women by 2014 .

As conventionalists disappeared, membership in the conventional realists and intensive parents' classes grew. Between 25 percent and 30 percent of white and black youth were conventional realists in 2014. Similarly, the intensive parent group become more prominent over time for all race-gender groups, but the likelihood of valuing a future as an intensive parent was greatest for young white women. In 2014 , about 31 percent of white women were in the intensive parent class compared with about 5 percent of white women in 1976.

Young black youth were more likely than white youth to be in the dual-earner group across the survey years. About 20 percent of young black women were classified as dual earners in 1976 and in 2014, showing a remarkably persistent proportion of young black women in this class. In the dual-earner class, the race gap decreased as the proportion of white youth increased over time. Across the classes, the attitude trends were remarkably similar across the race-gender groups, demonstrating that these beliefs reflect widely held norms.

\section{Discussion}

The prevailing wisdom within gender and work scholarship suggests that people increasingly hold gender egalitarian ideals yet they have been unable to implement their egalitarian preferences because of institutional constraints, like inflexible work schedules and lack of paid parental leave policies (Cotter et al. 2011; Jacobs and Gerson 2016; Pedulla and Thébaud 2015; Scarborough et al. 2018; Thébaud and Halcomb 2019). This explanation generally considers growing acceptance of mothers' employment as evidence of growing support for gender equality broadly. We question whether narrow measures of the acceptability of mothers' employment overestimate the deterioration of conventional attitudes about gender as an 


\section{Conventional}

Neotraditional

$0 \%$

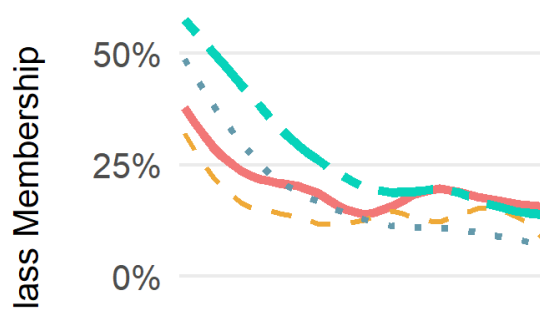

Dual-earners
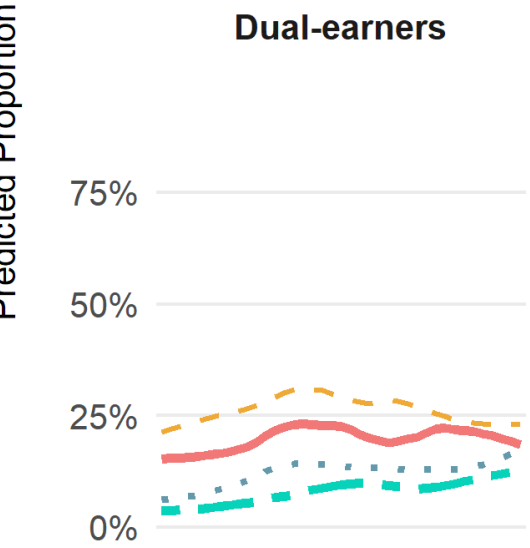

1976

\section{Intensive Parents}
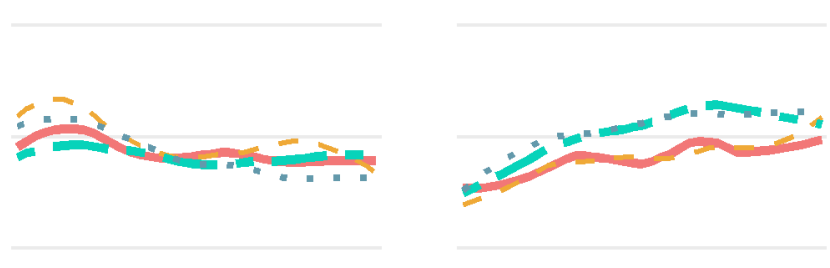

1976

\title{
Conventional Realists
}

\author{
Race \& Gender \\ - Black men \\ - - Black women \\ - - White men \\ - White women
}

Figure 3: Predicted proportion of latent class membership from 1976 to 2014 by race and gender.

organizing structure. We assessed changes in division of labor preferences over 40 years, simultaneously evaluating the appropriate roles for men and women in both public (workplace) and private (family) contexts. If the primary barrier to continued gender equality is explained by institutional constraints and not essentialist gender beliefs about appropriate behavior for men and women, we anticipated increasing proportions of youth desiring dual-earner arrangements or equal desires for one parent, regardless of gender, staying at home.

Findings showed little support for the growth of gender egalitarian ideals, suggesting institutional constraints are not the (only) barrier to gender progress. Although there was increasing diversity in expectations about future family life among respondents, conventional gender norms that prioritize fathers' employment while holding mothers' employment as secondary remain intact. We also found no substantial increase in youths' desire for gender atypical arrangements, even as 
these arrangements became more acceptable. Results from the LCA revealed that none of the clusters could be described as gender egalitarian-where support for time at home and in employment was equally prioritized between mother and fathers. Some scholars have suggested that men not adopting behaviors typically seen as feminine may be one mechanism contributing to the stalled gender revolution, and our results support that assertion (England 2010; Friedman 2015).

We demonstrated that prior research is likely overstating egalitarian attitudes by conflating acceptability of mothers' labor force participation with the adoption of gender egalitarian principles. Our data enabled us to evaluate whose employment was prioritized and not just tolerated. Distinguishing between desire and acceptance aligns with the divergence in fallback strategies that Gerson (2011) found among young men and women over the same survey years. Acceptance may be more akin to tolerance, which reflects a basic extension of civility tied to rights-based principles rather than a robust desire for gender equality (Brooks and Bolzendahl 2004). Other empirical evidence also suggests this distinction could be important theoretically. A 2017 study found the majority of people reported that it should not matter if the parent taking on greater responsibility for childcare was the mother or father, but these same respondents also believed others expected conventional gender behavior (Horowitz et al. 2017). Notably, this study did not ask respondents what they desired for their own families. Respondents in our data ranked desires for their own future family, which provides insights that cannot be gleaned from questions about general acceptability of mothers in the workplace.

What appears to be support for gender equality on the surface-acceptance of both parents in the workforce-could also be attributed to reactions to a precarious economy (Cherlin 2014; Kalleberg 2011). Within this changing economic context, the desire for conventional division of labor arrangements may persist, but people believe it is impractical given the insecure and unequal labor market (Corse and Silva 2017; Shu and Meagher 2018; Silva 2013). Our results align with scholarship that finds that working class men and women desire a conventional man-as-earner/woman-as-homemaker division of labor arrangement but cannot afford to implement it (Corse and Silva 2017; Silva 2013). It is also consistent with findings that conventional gender attitudes are correlated with the rise of men's overwork (Shu and Meagher 2018). Our conclusions support theoretical predictions that a convergence in men's and women's behavior is driven by economic and political changes, even if gender egalitarian attitudes are not widely embraced (Jackson 2006).

Although there were few meaningful differences between demographic groups, suggesting these attitudes are quite normative, our results showed that trends in division of labor attitudes primarily differ by race rather than gender. Black families have long adopted a "work-family integration" schema, in which parents are "co-breadwinners" and women hold dual-identities as workers-mothers (Dean, Marsh, and Landry 2013). The racialized history of the labor market required black families to adopt flexible division of labor arrangements in order to make ends meet (Bertrand and Mullainathan 2004; England, Garcia-Beaulieu, and Ross 2004; Pager, Western, and Bonikowski 2009). Our results suggest black youth may anticipate black men's employment precarity (Bertrand and Mullainathan 2004; 
Pager et al. 2009) and norms of integrated motherhood, valuing mothers' work outside the home and prioritizing financial self-reliance (Blum and Deussen 1996; Christopher 2013; Dow 2016; Elliott, Powell, and Brenton 2015). Future research could investigate the mechanisms underlying race differences in division of labor attitudes to better understand these distinctions.

Our analyses make the implicit assumption that all youth desire marriage and children, which may not be universal goals. The vignette that comprises our dependent variable asked about division of labor specifically within marriage, not about cohabitation or other partnership arrangements. Alternative scenarios outside of marriage may lead youth to express different expectations about desired work and family responsibilities. Our calculations from the Monitoring the Future data show that 79 percent of youth in 2014 expected to get married in the future, a comparable percentage to youth in the 1970s. Similarly, about 80 percent of youth in 1976 and in 2014 reported they will likely have children in the future. Consequently, marital and parental aspirations should not influence our results. In analyses not shown, we included an indicator of whether youth expected to get married to see if these expectations were associated with their attitudes about the division of labor. Findings revealed little differentiation by youths' marital aspirations in their evaluation of the arrangements over time. The vignette also excludes same-sex couples by explicitly asking about the division of labor between a husband and wife. This is a potential avenue for future scholarship.

There are several pertinent follow-up questions that unfortunately we cannot answer due to limitations of the Monitoring the Future data set. First, we cannot distinguish between housework and childcare in our measure of time at home. There may be important differences in perceptions if the vignette scenario separated preferences for mother's and father's time spent on housework and childcare (Bianchi et al. 2000, 2012; Sayer 2016; Sayer et al. 2009). Secondly, household income measures were not available in the data set, which may be an important predictor of division of labor attitudes. We included respondents' mother's highest level of education, sometimes used as a proxy for economic resources, as a control variable in all analyses. As an additional robustness check, we conducted a series of multinomial logistic regressions for each of the division of labor arrangements and interacted mother's education and survey year. The predicted proportion of youths' assessments of division of labor arrangements by respondents' mothers' education are presented in Figure B of the online supplement. The results showed little differentiation by mothers' education in youths' evaluation of the arrangements. Figure D in the online supplement shows the predicted proportion of latent class membership by respondents' mothers' education. Again, we found minimal variation in class membership by mothers' education.

It would be ideal to compare commonly used measures of gender attitudes, such as acceptance of mothers' labor force participation, with respondents' preferred division of labor scenarios. Unfortunately, gender attitude questions were not asked on form 2 of the Monitoring the Future questionnaire-the form that contains our dependent variables — so it's not possible to conduct this analysis with these data. According to our findings, the belief that women are primarily responsible for childcare and housework is persistent. It's possible that youth can't envision a 
different model about what men's time at home might look like, exhibited by their lackluster support for gender atypical arrangements. This illustrates the stickiness of gender. Experimental methods may be well-suited to investigate whether youths' attitudes would change if they could evaluate division of labor arrangements within a context of no institutional constraints, such as pay equality, affordable childcare, and parental leave. We encourage future research to pursue these questions.

These analyses show that it is essential to distinguish between gender flexibility in dividing time at work and at home from the adoption of gender egalitarian principles. Disentangling the underlying changes in attitudes about gender is important for understanding the future of the gender revolution, as we cannot address obstacles to equality without understanding what propels the revolution (Jackson 2006). We find that the fundamental bases of attitudes have shifted from traditionalism to gender flexibility but not gender equality.

\section{Notes}

1 Studies commonly rely on four gender attitude variables similar to those available in the General Social Survey (Cotter et al. 2011; Scarborough et al. 2018). Three of these indicators measure perceptions of mothers' employment, and one of the variables (FEFAM) is an attitudinal division of labor indicator that asks respondents to rank their agreement with the statement, "It is much better for everyone involved if the man is the achiever outside the home and the woman takes care of the home and family."

2 Monitoring the Future added a sixth questionnaire form in 1989; this did not affect our data or analysis.

3 The division of labor questions were no longer asked after 2014.

4 The seven-class model results in differentiation between two types of neotraditional clusters in which one cluster evaluated the gender atypical arrangements as "somewhat acceptable" and the other as "not at all acceptable." Our substantive conclusion is the same regardless of whether six or seven latent classes were used.

\section{References}

Bertrand, Marianne, and Sendhil Mullainathan. 2004. "Are Emily and Greg More Employable Than Lakisha and Jamal? A Field Experiment on Labor Market Discrimination." American Economic Review 94:991-1013. https ://doi .org/10.1257/0002828042002561.

Bianchi, Suzanne M., Melissa A. Milkie, Liana C. Sayer, and John P. Robinson. 2000. "Is Anyone Doing the Housework? Trends in the Gender Division of Household Labor." Social Forces 79:191-228. https://doi .org/10.2307/2675569.

Bianchi, Suzanne M., Liana C. Sayer, Melissa A. Milkie, and John P. Robinson. 2012. "Housework: Who Did, Does or Will Do It, and How Much Does It Matter?" Social Forces 91:55-63. https://doi.org/10.1093/sf/sos120.

Blum, Linda M., and Theresa Deussen. 1996. "Negotiating Independent Motherhood: Working-Class African American Women Talk about Marriage and Motherhood." Gender and Society 10:199-211. https://doi .org/10.1177/089124396010002007. 
Bolzendahl, Catherine I., and Daniel J. Myers. 2004. "Feminist Attitudes and Support for Gender Equality: Opinion Change in Women and Men, 1974-1998." Social Forces 83:759-89. https://doi.org/10.1353/sof . 2005.0005.

Bonikowski, Bart, and Paul DiMaggio. 2016. "Varieties of American Popular Nationalism." American Sociological Review 81:949-80. https://doi.org/10.1177/0003122416663683.

Brant, Rollin. 1990. “Assessing Proportionality in the Proportional Odds Model for Ordinal Logistic Regression." Biometrics 46:1171-78. https://doi .org/10.2307/2532457.

Braun, Michael. 2008. “Using Egalitarian Items to Measure Men's and Women's Family Roles." Sex Roles 59:644-56. https://doi.org/10.1007/s11199-008-9468-5.

Brewster, Karin L., and Irene Padavic. 2000. “Change in Gender-Ideology, 1977-1996: The Contributions of Intracohort Change and Population Turnover." Journal of Marriage and Family 62:477-87. https ://doi .org/10.1111/j.1741-3737.2000.00477.x.

Brooks, Clem, and Catherine Bolzendahl. 2004. "The Transformation of US Gender Role Attitudes: Cohort Replacement, Social-Structural Change, and Ideological Learning." Social Science Research 33:106-33. https ://doi .org/10.1016/s0049-089x (03)00041-3.

Carter, J. Scott, Mamadi Corra, and Shannon K. Carter. 2009. “The Interaction of Race and Gender: Changing Gender-Role Attitudes, 1974-2006." Social Science Quarterly 90:196-211. https://doi.org/10.1111/j.1540-6237.2009.00611.x.

Charles, Maria, and David Grusky. 2004. Occupational Ghettos: The Worldwide Segregation of Women and Men. Stanford, CA: Stanford University Press.

Cherlin, Andrew. 2014. Labor's Love Lost: The Rise and Fall of the Working-Class Family in America. New York, NY: Russell Sage Foundation.

Christopher, Karen. 2013. "African Americans' and Latinas' Mothering Scripts: An Intersectional Analysis." Pp. 187-208 in Advances in Gender Research. Vol. 17, edited by M. H. Kohlman, D. B. Krieg, and B. J. Dickerson. Bingley, United Kingdom: Emerald Group Publishing Limited. https://doi .org/10.1108/S1529-2126(2013)0000017012.

Collins, Linda M., and Stephanie T. Lanza. 2010. Latent Class and Latent Transition Analysis: With Applications in the Social, Behavioral, and Health Sciences. Hoboken, NJ: Wiley.

Cooper, Marianne. 2014. Cut Adrift: Families in Insecure Times. Oakland, CA: University of California Press.

Corse, Sarah M., and Jennifer M. Silva. 2017. "Intimate Inequalities: Love and Work in the Twenty-First Centuries." Pp. 283-303 in Beyond the Cubicle: Job Insecurity, Intimacy and the Flexible Self, edited by A. J. Pugh. New York, NY: Oxford University Press.

Cotter, David A., Joan M. Hermsen, and Reeve Vanneman. 2011. “The End of the Gender Revolution? Gender Role Attitudes from 1977 to 2008." American Journal of Sociology 117:259-89. https://doi.org/10.1086/658853.

Damaske, Sarah. 2011. For The Family? How Class and Gender Shape Women's Work. New York, NY: Oxford University Press.

Davis, Shannon N., and Theodore N. Greenstein. 2009. “Gender Ideology: Components, Predictors, and Consequences." Annual Review of Sociology 35:87-105. https : //doi . org/ 10.1146/annurev-soc-070308-115920.

Dean, Paul, Kris Marsh, and Bart Landry. 2013. "Cultural Contradiction or Integration? Work-Family Schemas of Black Middle Class Mothers." Pp. 137-58 in Advances in Gender Research. Vol. 17, edited by M. H. Kohlman, D. B. Krieg, and B. J. Dickerson. Bingley, United Kingdom: Emerald Group Publishing Limited. https://doi .org/10. 1108/s1529-2126(2013)0000017010. 
Doan, Long, and Natasha Quadlin. 2019. "Partner Characteristics and Perceptions of Responsibility for Housework and Child Care." Journal of Marriage and Family 81:145-63. https://doi.org/10.1111/jomf.12526.

Dow, Dawn Marie. 2016. "Integrated Motherhood: Beyond Hegemonic Ideologies of Motherhood: Integrated Motherhood." Journal of Marriage and Family 78:180-96. https : //doi.org/10.1111/jomf.12264.

Edin, Kathryn, and Timothy J. Nelson. 2013. Doing the Best I Can: Fatherhood in the Inner City. Berkeley, CA: University of California Press.

Elliott, Sinikka, Rachel Powell, and Joslyn Brenton. 2015. "Being a Good Mom: Low-Income, Black Single Mothers Negotiate Intensive Mothering." Journal of Family Issues 36:351-70. https://doi.org/10.1177/0192513×13490279.

England, Paula. 2006. “Toward Gender Equality: Progress and Bottlenecks." Pp. 245-64 in The Declining Significance of Gender?, edited by F. D. Blau, M. C. Brinton, and D. B. Grusky. New York, NY: Russell Sage Foundation.

England, Paula. 2010. “The Gender Revolution: Uneven and Stalled." Gender and Society 24:149-66. https://doi.org/10.1177/0891243210361475.

England, Paula, Carmen Garcia-Beaulieu, and Mary Ross. 2004. “Women's Employment among Blacks, Whites, and Three Groups of Latinas: Do More Privileged Women Have Higher Employment?" Gender and Society 18:494-509. https ://doi .org/10.1177/ 0891243204265632.

Flood, Sarah, Miriam King, Renae Rodgers, Steven Ruggles, and J. Robert Warren. 2018. Integrated Public Use Microdata Series, Current Population Survey: Version 6.0 [dataset]. Minneapolis, MN: IPUMS [distributor]. https://doi .org/10.18128/D030.V6.0.

Friedman, Sarah. 2015. "Still a 'Stalled Revolution'? Work/Family Experiences, Hegemonic Masculinity, and Moving Toward Gender Equality." Sociology Compass 9:140-55. https : //doi.org/10.1111/soc4.12238.

Gerson, Kathleen. 2009. "Changing Lives, Resistant Institutions: A New Generation Negotiates Gender, Work, and Family Change." Sociological Forum 24:735-53. https: //doi.org/10.1111/j.1573-7861.2009.01134.x.

Gerson, Kathleen. 2011. The Unfinished Revolution: Coming of Age in a New Era of Gender, Work, and Family. New York, NY: Oxford University Press.

Giddens, Anthony. 1992. The Transformation of Intimacy: Sexuality, Love, and Eroticism in Modern Societies. Stanford, CA: Stanford University Press.

Harris, Richard J., and Juanita M. Firestone. 1998. "Changes in Predictors of Gender Role Ideologies Among Women: A Multivariate Analysis." Sex Roles 38:239-52. https: //doi.org/10.1023/A:1018785100469.

Hays, Sharon. 1996. The Cultural Contradictions of Motherhood. New Haven, CT: Yale University Press.

Hershey, Marjorie Randon. 1978. "Racial Differences in Sex-Role Identities and Sex Stereotyping: Evidence Against a Common Assumption." Social Science Quarterly 58:583-96.

Hoffnung, Michele. 2004. “Wanting It All: Career, Marriage, and Motherhood During College-Educated Women's 20s." Sex Roles 50:711-23. https://doi.org/10.1023/b:sers.0000027572.57049.ff.

Horowitz, Juliana M., Kim Parker, Nikki Graf, and Gretchen Livingston. 2017. "Americans Widely Support Paid Family and Medical Leave, but Differ Over Specific Policies." Pew Research Center. http://pewrsr.ch/2nHlF45. 
Jackson, Robert Max. 2006. “Opposing Forces: How, Why, and When Will Gender Inequality Disappear?" Pp. 215-44 in The Declining Significance of Gender?, edited by F. D. Blau, M. C. Brinton, and D. B. Grusky. New York, NY: Russell Sage Foundation.

Jacobs, Jerry A., and Kathleen Gerson. 2005. The Time Divide: Work, Family, and Gender Inequality. Cambridge, MA: Harvard University Press.

Jacobs, Jerry A., and Kathleen Gerson. 2016. “Unpacking Americans' Views of the Employment of Mothers and Fathers Using National Vignette Survey Data SWS Presidential Address." Gender and Society 30:413-41. https ://doi .org/10.1177/0891243215597445.

Johnston, Lloyd D., Jerald G. Bachman, Patrick M. O'Malley, John E. Schulenberg, and Richard A. Miech. 2017. Monitoring the Future: A Continuing Study of American Youth (12th-Grade Survey), 2014 (ICPSR 36263). Inter-university Consortium for Political and Social Research [distributor]. https://www.icpsr.umich.edu/icpsrweb/NAHDAP/ studies/36263/version/3.

Kalleberg, Arne L. 2011. Good Jobs, Bad Jobs: The Rise of Polarized and Precarious Employment Systems in the United States, 1970s to 2000s. New York, NY: Russell Sage Foundation.

Kane, Emily W. 2000. "Racial and Ethnic Variations in Gender-Related Attitudes." Annual Review of Sociology 26:419-39. https : //doi .org/10.1146/annurev . soc . 26 .1.419.

Kane, Emily W., and Laura Sanchez. 1994. "Family Status and Criticism of Gender Inequality at Home and at Work." Social Forces 72:1079-102. https : //doi .org/10.2307/2580293.

Knight, Carly R., and Mary C. Brinton. 2017. “One Egalitarianism or Several? Two Decades of Gender-Role Attitude Change in Europe." American Journal of Sociology 122:1485-532. https://doi.org/10.1086/689814.

Linzer, Drew A., and Jeffrey Lewis. 2013. PoLCA: Polytomous Variable Latent Class Analysis.

Livingston, Gretchen, and Kim Parker. 2019. "8 Facts About American Dads." Pew Research Center. https://www.pewresearch.org/fact-tank/2019/06/12/ fathers-day-facts/.

Mason, Karen Oppenheim, and Yu-Hsia Lu. 1988. “Attitudes toward Women's Familial Roles: Changes in the United States, 1977-1985." Gender and Society 2:39-57. https: //doi.org/10.1177/089124388002001004.

Meagher, Kelsey D., and Xiaoling Shu. 2019. “Trends in U.S. Gender Attitudes, 1977 to 2018 : Gender and Educational Disparities." Socius 5:2378023119851692. https://doi .org/10. $1177 / 2378023119851692$.

Nylund, Karen L., Tihomir Asparouhov, and Bengt O. Muthén. 2007. “Deciding on the Number of Classes in Latent Class Analysis and Growth Mixture Modeling: A Monte Carlo Simulation Study." Structural Equation Modeling: A Multidisciplinary Journal 14:53569. https://doi.org/10.1080/10705510701575396.

Pager, Devah, Bruce Western, and Bart Bonikowski. 2009. "Discrimination in a Low-Wage Labor Market: A Field Experiment." American Sociological Review 74:777-99. https: //doi.org/10.1177/000312240907400505.

Pedulla, David S., and Sarah Thébaud. 2015. "Can We Finish the Revolution? Gender, Work-Family Ideals, and Institutional Constraint." American Sociological Review 80:116-39. https://doi.org/10.1177/0003122414564008.

Pepin, Joanna R., and David A. Cotter. 2018. "Separating Spheres? Diverging Trends in Youth's Gender Attitudes About Work and Family." Journal of Marriage and Family 80:7-24. https://doi.org/10.1111/jomf .12434.

Raftery, Adrian E. 1995. "Bayesian Model Selection in Social Research." Sociological Methodology 25:111-63. https ://doi .org/10.2307/271063. 
Raley, R. Kelly, Sarah Crissey, and Chandra Muller. 2007. "Of Sex and Romance: Late Adolescent Relationships and Young Adult Union Formation." Journal of Marriage and Family 69:1210-26. https://doi .org/10.1111/j.1741-3737.2007.00442.x.

Sayer, Liana C. 2005. “Gender, Time and Inequality: Trends in Women's and Men's Paid Work, Unpaid Work and Free Time." Social Forces 84:285-303. https://doi.org/10. 1353 /sof .2005.0126.

Sayer, Liana C. 2016. “Trends in Women's and Men's Time Use, 1965-2012: Back to the Future?" Pp. 43-78 in Gender and Couple Relationships, Pennsylvania State University National Symposium on Family Issues (NSFI), edited by S. M. McHale, V. King, J. Van Hook, and A. Booth. New York, NY: Springer International Publishing.

Sayer, Liana C., Paula England, Michael Bittman, and Suzanne M. Bianchi. 2009. "How Long Is the Second (Plus First) Shift? Gender Differences in Paid, Unpaid, and Total Work Time in Australia and the United States." Journal of Comparative Family Studies 40:523-45. https://doi.org/10.3138/jcfs.40.4.523.

Scarborough, William J., Ray Sin, and Barbara Risman. 2018. "Attitudes and the Stalled Gender Revolution: Egalitarianism, Traditionalism, and Ambivalence from 1977 through 2016." Gender and Society 33:173-200. https://doi .org/10.1177/0891243218809604.

Schnabel, Landon. 2018. "More Religious, Less Dogmatic: Toward a General Framework for Gender Differences in Religion." Social Science Research 75:58-72. https://doi . org/10. 1016/j.ssresearch.2018.06.010.

Schwarz, Gideon. 1978. "Estimating the Dimension of a Model." The Annals of Statistics 6:461-64.

Sherman, Rachel. 2017. Uneasy Street: The Anxieties of Affluence. Princeton, NJ: Princeton University Press.

Shu, Xiaoling, and Kelsey D. Meagher. 2018. "Beyond the Stalled Gender Revolution: Historical and Cohort Dynamics in Gender Attitudes from 1977 to 2016." Social Forces 96:1243-74. https://doi.org/10.1093/sf/sox090.

Silva, Jennifer M. 2013. Coming Up Short: Working-Class Adulthood in an Age of Uncertainty. New York, NY: Oxford University Press.

Tallichet, Suzanne E., and Fern K. Willits. 1986. “Gender-Role Attitude Change of Young Women: Influential Factors from a Panel Study." Social Psychology Quarterly 49:219-27. https://doi.org/10.2307/2786804.

Thébaud, Sarah, and Laura Halcomb. 2019. “One Step Forward? Advances and Setbacks on the Path toward Gender Equality in Families and Work." Sociology Compass 13:1-15. https://doi.org/10.1111/soc4.12700.

Thornton, Arland, and Linda Young-DeMarco. 2001. "Four Decades of Trends in Attitudes Toward Family Issues in the United States: The 1960s Through the 1990s." Journal of Marriage and Family 63:1009-1037. https://doi.org/10.1111/j.1741-3737.2001. 01009.x.

Walter, Jessica Gabriele. 2018. "The Adequacy of Measures of Gender Roles Attitudes: A Review of Current Measures in Omnibus Surveys." Quality and Quantity 52:829-48. https://doi.org/10.1007/s11135-017-0491-x.

Western, Bruce, Deirdre Bloome, Benjamin Sosnaud, and Laura Tach. 2012. "Economic Insecurity and Social Stratification." Annual Review of Sociology 38:341-59. https://doi . org/10.1146/annurev-soc-071811-145434.

Williams, Joan C., Mary Blair-Loy, and Jennifer L. Berdahl. 2013. “Cultural Schemas, Social Class, and the Flexibility Stigma." Journal of Social Issues 69:209-34. https : //doi .org/ 10.1111/josi.12012. 
Yodanis, Carrie, and Sean Lauer. 2014. "Is Marriage Individualized? What Couples Actually Do." Journal of Family Theory and Review 6:184-97. https://doi.org/10.1111/jftr. 12038.

Acknowledgments: We thank Kelly Raley, Melissa Milkie, Philip Cohen, and Sarah Flood for generously reading previous versions and providing invaluable feedback. This article was presented at the University of Maryland's Gender, Work, and Family/Stratification working group, the Family Demography working group at the University of Texas, and at the 2018 American Sociological Association's annual conference. We thank all the audience participants for their thoughtful comments. Replication code for data access and all paper analyses are available at https://osf.io/m3xwy/.

This research was supported by grant P2CHD042849, Population Research Center, and grant T32HD007081, Training Program in Population Studies, awarded to the Population Research Center at The University of Texas at Austin; and grant P2CHD041041, Maryland Population Research Center, awarded to the University of Maryland, by the Eunice Kennedy Shriver National Institute of Child Health and Human Development. The content is solely the responsibility of the authors and does not necessarily represent the official views of the National Institutes of Health.

Brittany N. Dernberger: Department of Sociology, University of Maryland.

E-mail: bdernber@terpmail.umd.edu.

Joanna R. Pepin: Population Research Center, University of Texas at Austin.

E-mail: JPepin@prc.utexas.edu. 